\title{
Screening of bovine milk samples for sub-clinical mastitis and antibiogram of bacterial isolates
}

\author{
Harini H. and Sumathi B. R.* ${ }^{1}$ \\ Veterinary Hospital, Department of Animal Husbandry and Veterinary Services. Kanakapura, \\ Ramanagara District, Karnataka state - 562117, India. \\ 1. Insitute of Animal Health and Veterinary Biologicals, Hebbal, Banglore, Karnataka, India. \\ * Corresponding author email : scientistproduction@gmail.com
}

Received: 31-12-2010 Accepted: 28-01-2011, Published Online: 04-06-2011

\begin{abstract}
The study was undertaken to find out the incidence of subclinical mastitis (SCM) and to assess the antibiotic sensitivity pattern of the causative organisms in lactating cows in and around Kanakapura taluk, Ramanagara district of Karnataka state. The prevalence of subclinical mastitis was assessed by the results of 3 different screening tests and bacteriological evaluation was done for the milk samples that were found positive. The predominant bacterial isolates recovered were Staphylococcus aureus (58\%) and Escherichia coli (23.5\%) followed by Staphylococcus epidermidis (8\%), Streptococcus sp. (5.5\%), Klebsiella sp. (3\%) and Bacillus sp. (2\%). The in vitro antibiogram studies of bacterial isolates revealed higher sensitivity for ciprofloxacin (89\%), ofloxacin $(85 \%)$, enrofloxacin $(82 \%)$, gentamicin $(80 \%)$ and chloramphenicol (75\%), resistant to colistin, neomycin, streptomycin, penicillin and tetracycline.
\end{abstract}

Key words: Subclinical, Screening, Antibiotic sensitivity and Prevalence.

Subclinical Mastitis causes higher economic losses to farmers. Subclinical mastitis goes without diagnosis. So, The study was undertaken to find out the incidence of subclinical mastitis (SCM) and to assess the antibiotic sensitivity pattern of the causative organisms in lactating cows in and around Kanakapura taluk, Ramanagara district of Karnataka state.

\section{Materials and Methods}

Sources of milk samples: A total of 250 milk samples from lactating cows in and around Kanakapura taluk, Ramanagaram district were screened for subclinical mastitis by white side test, california mastitis test and chloride test (Schalm et al., 1971). The samples were subjected to bacteriological study in the regional laboratory by inoculating approximately $0.01 \mathrm{ml}$ of milk sample on to blood agar, nutrient agar, MacConkey's agar and Eosine Methylene Blue agar plates and the plates were incubated "under aerobic conditions" at $37^{\circ} \mathrm{C}$ for 24 to 48 hours. The staining and cellular morphological features of organisms were ascertained by microscopic examination of Gram stained smears. The bacteria isolated were identified on the basis of their cultural, morphological and biochemical characteristics as per the method of (Cruickshank et al., 1975).

The in-vitro antibiotic sensitivity test of bacterial isolates was conducted on Mueller Hinton agar (M/s
Hi Media Laboratories Ltd., Mumbai) plates against commonly used antibiotics in the field as per the method of Bauer et al. (1966). Minimal Inhibitory Concentration (MIC) values of the bacterial organisms were analyzed against common antibiotic discs (M/s Hi Media Laboratories Ltd., Mumbai). The following antibiotic discs namely chloramphenicol $(30 \mu \mathrm{g})$, ofloxacin $(10 \mu \mathrm{g})$, ciprofloxacin $(10 \mu \mathrm{g})$, colistin (Methane sulphonate $(25 \mu \mathrm{g})$, enrofloxacin $(10 \mu \mathrm{g})$, penicillin (10 I.U.), gentamicin $(30 \mu \mathrm{g})$, tetracycline $(30 \mu \mathrm{g})$, neomycin $(30 \mu \mathrm{g})$, streptomycin $(10 \mu \mathrm{g})$ were used.

\section{Results and Discussion}

Screening of milk samples from 250 cows by the three tests revealed $75 \%$ (175) cows to be affected with SCM. Cultural examination of positive samples revealed higher incidence of Staphylococcal mastitis. Out of 175 samples, 105 samples $(60 \%)$ yielded pure and the remaining $70(40 \%)$ yielded mixed cultures. Totally 200 bacterial cultures were recovered. The predominant bacterial isolates were Staphylococcus aureus $(58 \%)$ and Escherichia coli $(23.5 \%)$ followed by Staphylococcus epidermidis (8\%), Streptococcus sp. (5.5\%), Klebsiella sp. (3\%) and Bacillus sp. (2\%). The frequency of isolation of different bacterial species from subclinical mastitis cases is depicted in Table1.

The in vitro antibiogram studies of bacterial isolates revealed higher sensitivity for ciprofloxacin 
Screening of bovine milk samples for sub-clinical mastitis and antibiogram of bacterial isolates

Table-1. Frequency of different bacterial isolates from bovine mastitis cases.

\begin{tabular}{clcc}
\hline Sr. No & Bacterial species & No.of Isolates & Percent \\
\hline 1. & Staphylococcus aureus & 116 & 58.00 \\
2. & Escherichia coli & 47 & 23.50 \\
3. & Staphylococcus epidermidis & 16 & 8.00 \\
4. & Streptococcus sp. & 11 & 5.50 \\
5. & Klebsiella sp. & 6 & 3.00 \\
6. & Bacillus sp. & 4 & 2.00 \\
\hline
\end{tabular}

$(89 \%)$, ofloxacin $(85 \%)$, enrofloxacin $(82 \%)$, gentamicin $(80 \%)$ and chloramphenicol (75\%), resistant to colistin, neomycin, streptomycin, penicillin and tetracycline. Ofloxacin, enrofloxacin, ciprofloxacin, chloramphenicol and gentamicin are less commonly used for treatment of mastitis in the area of study resulting in higher efficacy of these drugs. More number of isolates showed moderate sensitivity or resistance to colistin, neomycin, penicillin, streptomycin and tetracycline. Indiscriminate and frequent use of these antibiotics in animals could be the reason for their ineffectiveness against bacterial isolates. Similar antibiogram pattern were reported by Bhattacharya (2002), Goswami et al (2002), Ghose et al (2003) and Chhabra and Arora (2006) .

\section{Acknowledgement}

Authors are thankful to R. Ramesh, Asst. Director,
Kanakapura Veterinary hospital and Dr. Guruvayya, Asst. Director, Ramanagar Veterinary hospital for providing necessary facilities and help for the experiment.

\section{References}

1. Bauer, A.W., Kirby, W.M.M., Sharria, J. C. and Turk, M. (1966) American J. Clin. Pathol., 45:493.

2. Bhattacharya, A. (2002) Indian Vet. J., 79:961.

3. Chabra, D. and Arora, S. (2006) Indian Vet. J., 83:1333.

4. Cruickshank, R., Duguid, J.P., Marmion, B.P. and Swain, R.H.A. (1975) Medical Microbiology. Vol. II, 12th edn, CrurchillLivingstone, New York, 31-57p \& 96-218p.

5. Ghose, B., Sharda, Chabra, D. and Sharma, V. (2003) ibid., 80:499.

6. Goswami, P., Biswas, S. and Podder, R.C. (2002) Isolation and antibiogram of bacterial isolates from clinical mastitis Indian J. Anim. Health., 41:52-54.

7. Schalm, O.M., Carroll, E.J. and Jain, N.C. (1971) Bovine Mastitis. $1^{\text {st }}$ edn., Lea Febiger, Philadelphia. 